\title{
UNA NUEVA ESPECIE DE BATESIMALVA (MALVACEAE) DE COAHUILA, MEXICO
}

\author{
Jose A. Villarreal-Quintanilla \\ Universidad Autónoma Agraria "Antonio Narro" \\ Buenavista, Saltillo, Coahuila, 25315, México \\ P.A. FRYXELL \\ U.S. Dept. Agriculture, Texas A\&M University \\ College Station, Texas 77843, E.E. U.U.
}

\begin{abstract}
RESUMEN
Se describe una especie de Batesimalva (Malvaceae) para el suroeste del estado de Coahuila, la cual difiere de las especies ya conocidas por sus hojas palmatipartidas, estípulas más largas, cáliz más dividido y su menor estatura. Se incluye una ilustración.
\end{abstract}

\section{ABSTRACT}

A new species of Batesimalva (Malvaceae) is described from the southwestern part of the state of Coahuila. It differs from the known species in its palmately parted leaves, longer stipules, deeply divided calyx and its smaller height. An illustration is included.

El género Batesimalva comprendía dos especies mexicanas (Fryxell, 1988), además de una tercera, disyuntiva y disímil, de Venezuela (Fryxell, 1985). El reciente descubrimiento de una especie adicional del norte de México, descrita en seguida, aumenta su número a cuatro, amplía el área geográfica conocida del género al oeste (de Coahuila), y agranda el alcance de su variabilidad morfológica. La característica principal que sirve para unificar a Batesimalva es la morfología distintiva del fruto.

\section{Batesimalva lobata Villarreal \& Fryxell sp. nov.}

Fruticulus caulibus pubescentibus pilis stellatis $0.5 \mathrm{~mm}$ diametro; laminis foliorum 1.5$3 \mathrm{~cm}$ longis palmatim 3-5-lobatis, petiolis laminas subaequantibus, stipulis subulatis $2-3 \mathrm{~mm}$ longis; floribus solitariis pedicellis $3-4 \mathrm{~cm}$ longis; calycibus $7-10 \mathrm{~mm}$ longis profunde 5-partitis; petalis malvinis 10-12 mm longis; fructibus 10-12 mm diametro, mericarpiis $8-10$ unumquidque in cellulas duas per endoglossum divisum, cellulis infernis indehiscentibus lateraliter reticulatis 1 -seminalibus, cellulis supernis inanibus dehiscentibus inflatis atque dorsaliter prolongatis. 
Arbustito de 20-60 cm de alto, tallos jóvenes verdes, con pubescencia estrellada,los pelos de $0.5 \mathrm{~mm}$ de diámetro. Hojas alternas, láminas de $1.5-3 \mathrm{~cm}$ de largo, $1.2-2.5 \mathrm{~cm}$ de ancho, discoloras, el haz verde oscuro, con pelos estrellados esparcidos; el envés más claro, con pubescencia estrellada más densa, base cordada, margen palmatipartido en 3-5 lóbulos, los lóbulos esparcidamente crenados, pecíolo de 1-3 cm largo, con pubescencia de pelos estrellados y algunos pelos simples de 1-2 $\mathrm{mm}$ de largo, estípulas subuladas, pubescentes, persistentes, de 2-3 mm de largo. Flores solitarias, axilares, sobre pedicelos de 3-4 $\mathrm{cm}$ de largo, con pubescencia estrellada, a veces con pigmentación morada oscura en un lado, aparentemente sin articulación; calículo ausente; cáliz profundamente 5-partido, de 7$10 \mathrm{~mm}$ de largo, con pubescencia estrellada, los lóbulos angostamente lanceolados, de 5-8 $\mathrm{mm}$ de largo y 2-3 mm de ancho en la base, sin venación evidente; pétalos lilas (a veces blancos cuando secos), de 10-12 mm de largo, glabros pero con algunos pelos en el margen de la uña; columna estaminal de $4 \mathrm{~mm}$ de largo, de color amarillo pálido, glabra, parte libre de los filamentos de 1-2 mm de largo, anteras y polen amarillos; estilos 8-10, sobrepasando el androceo, de color amarillo pálido, con estigmas capitados. Frutos circulares, de 10-12 $\mathrm{mm}$ de diámetro, con 8-10 lóbulos, con pubescencia estrellada, generalmente con pigmentación oscura en las partes expuestas; mericarpios 8-10, de $5 \mathrm{~mm}$ de largo y $4 \mathrm{~mm}$ de alto, con dos cavidades, la más baja con paredes laterales reticuladas, indehiscente, con una sola semilla y con una pequeña lengua (endoglosa) que separa las dos cavidades, la cavidad superior sin semilla, algo inflada, lisa y prolongada dorsalmente, que al abrir forma dos alas; semillas vagamente triangulares, de $2.2 \mathrm{~mm}$ de largo y $1.8 \mathrm{~mm}$ de ancho, de color café oscuro, con pubescencia corta, esparcida.

TIPO: México, Coahuila, Mpio. Torreón, Sierra de Jimulco, $150 \mathrm{~m}$ al E de la Mina de

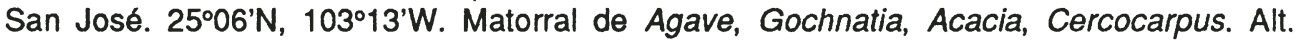
2100 m. 21 octubre 1989. J. A. Villarreal 5512, P. A. Fryxell, J. Valdés y P. Peterson. (Holotipo: MEXU; Isotipos: ANSM, TEX, pf*, ENCB).

Material adicional examinado: Localidad tipo, 25 agosto 1988. J. A. Villarreal 4419. (ANSM, pf ).

El nuevo taxon se distingue de las otras especies mexicanas de Batesimalva por las hojas palmatipartidas, las estípulas bien desarrolladas, el cáliz profundamente partido, y por su estatura más pequeña. Crece usualmente entre arbustos de Parthenium, Gochnatia y Agave en las laderas de la sierra con suelos pedregosos y rocas calizas. La floración ocurre durante el verano (julio-octubre) después de la temporada de lluvias.

\section{AGRADECIMIENTOS}

Agradecemos a Karin Douthit la elaboración de la ilustración. A los biólogos A. Rodríguez G., M. A. Carranza, J. Valdés R. y P. Peterson su colaboración en los viajes de colecta.

El símbolo pf corresponde al herbario particular de Paul A. Fryxell. 


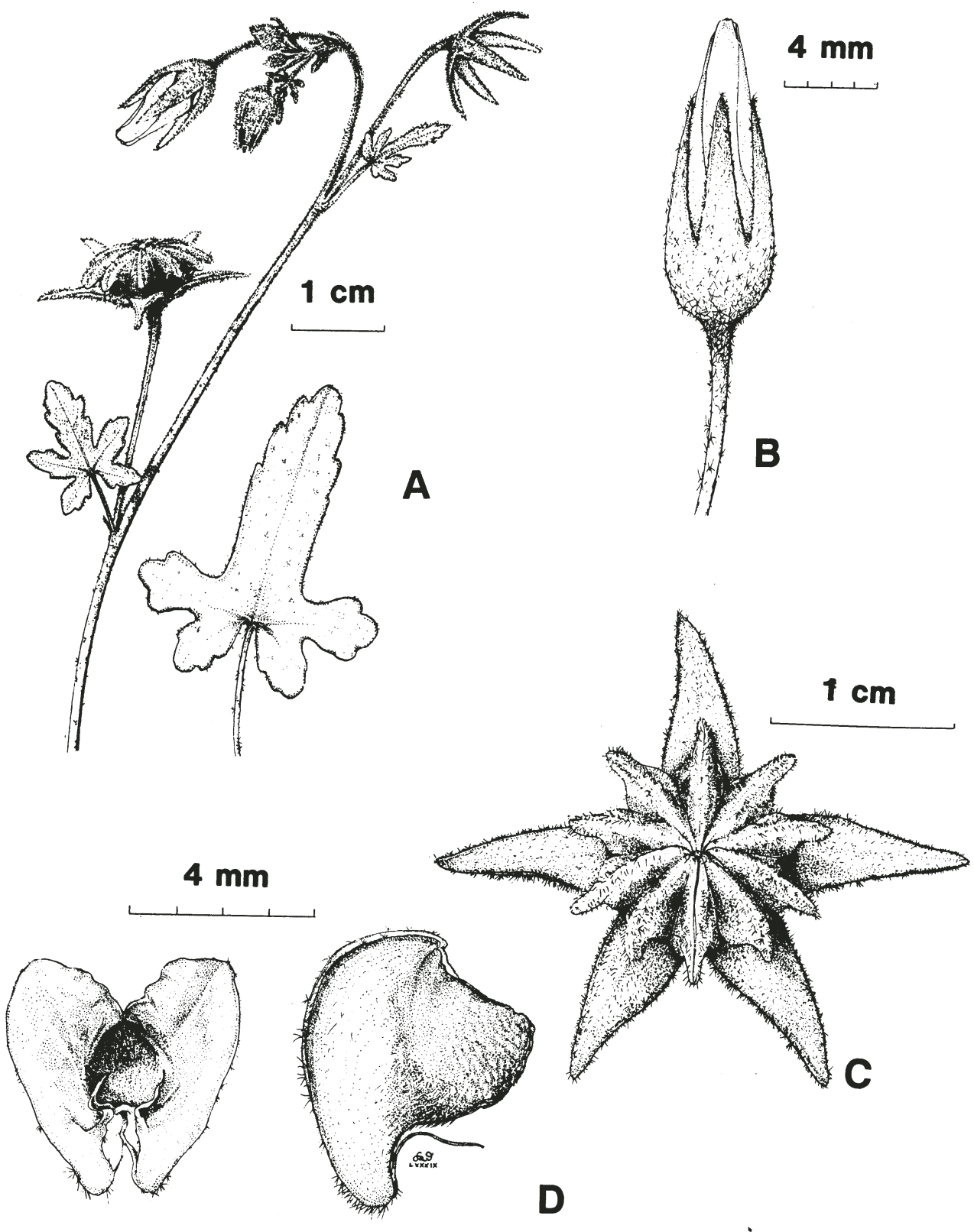

Fig. 1. Batesimalva lobata Villarreal \& Fryxell. A. Rama con botones y un fruto, hoja de la base; B. Botón; C. Fruto; D. Mericarpio individual en vista superior, mostrando la semilla y la endoglosa, en vista lateral. (Villarreal \& Carranza 4419). 
Acta Botánica Mexicana (1990), 11:19-22

\section{LITERATURA CITADA}

Fryxell, P.A. 1985. Four new species of Malvaceae from Venezuela. Syst. Bot. 10:273-281.

Fryxell, P.A. 1988. Malvaceae of Mexico. Syst. Bot. Monogr. 25:1-522. 